\title{
Editorial
}

\section{Femicide and Culture}

by

Christiana Kouta

Cyprus University of Technology

Cyprus

christiana.kouta@cut.ac.cy

Anita Nudelman

Ben Gurion University

Israel

anitanudelman@gmail.com

Anne Ryen

University of Agder

Norway

anne.ryen@uia.no

\section{(c) (i) (2)}

This work is licensed under a Creative Commons Attribution-ShareAlike 4.0 International License. 
Violence against women is an increasing problem in today's world. It is a violation of human rights, a social problem and a public health problem (Bott et al., 2013). Violence against women is also a persistent problem. In particular, this may occur at the intersection of power, poverty (Firth, 2014).

Femicide is the most extreme form of violence, and is generally understood to involve the intentional murder of women simply because they are women or girls (WHO, 2012). Among others, women are killed in their homes or at work for ending abusive relationships or for 'honour' or dowry-related issues. Femicide seems to be an epidemic throughout the world, and the consequences for the family and community can be enormous. For example, children whose mother has been killed by their father suffer long-term psychological, psychiatric and social problems (Kapardis et al., 2017).

It is important while discussing violence against women to question the cultural factors that may cause and/or sustain it. Culture is a highly influential parameter that shapes individual behaviour, including violence (WHO, 2009). A variety of external and internal pressures are thought to maintain cultural and social norms, such as specific gender roles within a community or culture. Feminist cultures provide equal power to both men and women. Violence is more likely to occur in cultures that foster beliefs of perceived male superiority, and the social and cultural inferiority of women (Kalra \& Bhugra, 2013). Culture influences the socialization of boys and girls, as well as their understandings about different things such as gender roles, violence, family and so forth. Addressing culture and violence is challenging, as in some societies cultural underpinnings make it easier for people and society to 'accept' violence. Kalra and Bhugra (2013) argue that fundamentalism - the use of religion for power and control has an impact on other identity characteristics such as culture, tradition, nationalism and ethnicity.

Everyone should have the freedom of thought, conscience and religion. Therefore, the Vienna Declaration on Femicide (2013) emphasizes that traditions and culture cannot be used as justifications for the violation of women's human rights, in particular the right to life and the right to be free from violence. In all cultures, there is a range of different interpretations and understandings, practices and beliefs, in addition to the possibility of transformation and change (Gokal \& Dughman Manzur, 2013). Socio- 
ecological theories are important, as they provide a holistic view and understanding of violence against women. Thus, it goes beyond individual, sociocultural or situational factors only, also including a multidimensional interplay among them (Saccomano, 2015).

Different movements were formed against femicide. Starr (2017) argues that the more culturally relevant the framings, the greater chances that a movement has of being successful. Framing theory in social movements is an analytical tool for examining the symbols, slogans, and underlying messages that provide the public with a way to interpret, or frame, a movement resonant with the host culture (Starr, 2017: 1359). Therefore, government and other opposition views must be considered when constructing these frames, and thus may help to be successful in fighting (in this case) femicide.

Although much research has been done worldwide, in Europe femicide lags behind. Nowadays, in some European countries, cultural factors contribute to instances of femicide. Hence, it is of interest to view and analyse femicide-related research in Europe, and consider relevant aspects such as traditional values, gender roles and media coverage (Kouta et al., 2017).

This special issue offers six articles from various regions across the world. They all deal with femicide and culture in their own ways, and we find an interesting variation in both focus and methods. It reminds us of the complexity of femicide, with its many forms and variation in frequency. Murders also involve larger groups beyond the victims themselves, such as survivors, children and other family members. In addition, we find many professionals and volunteers who work to prevent femicide and assist victims. Lastly, the context in which the murders take place, be it local communities or larger societal structures, should also be considered, some of them are described as patriarchal with a violent culture, others as peaceful. This also shapes people's - both survivors' and perpetrators'- perception and storytelling of this phenomenon, and of their own experiences. The articles clearly remind us of the culture of femicide, which includes how women are killed, how it is narrated, how the media portrays it and how it is dealt with. As a result, femicide is always a contextual phenomenon and never an isolated instance. The articles in this edition show that gender issues appear in diverse 
ways, which at times may be unexpected for people outside a certain culture. Based on their data, some articles make us clearly see that policies to fight femicide, and to care for victims of gender-based violence must be contextually grounded, and that the wider apparatus varies as to extent and professionalization. Also, people's trust in welfare's front-desk personnel varies, as well as their experiences with people they assume would assist them, and sometimes, despite high trust, there may be other institutional hurdles. The articles show that we cannot take for granted that a woman's death is always seen as a tragedy or as social disorder. Some see it as justified for a variety of reasons, and rather a reflection of social order. Gender matters, and the gendering of lives comes with systematic gendered consequences. This reminds us of murder as a social phenomenon shaped by how people in their everyday interaction come to talk about it and name it, and this frames whether the murder of a woman is perceived as a tragedy, as justified or even celebrated. Culture is reflected in how we perceive, interpret and react in our daily lives, and cannot always be predicted (Ryen, 2008). This accounts for the variations seen in the articles included in this special edition. It also reminds us that it is not the acts themselves that decide, but how we come to see them and talk about them; it is also how media, police and other actors react relate to, deal with and portray when a woman is stabbed to death, shot, strangled or killed in other ways by an intimate partner or family member, or when the victim sees suicide as the only viable solution to a life in constant pain.

Two of the articles analyse media. In her article, 'She knew he would murder her': The role of media in reconstruction of intimate femicide, Revital Sela-Shayovitz is concerned with how media constructs intimate femicide, and explores how different social groups such as Israeli Jews, Israeli Arabs and immigrants from Ethiopia frame intimate femicide in Israeli society. It is based on newspaper articles, with the researcher using both a quantitative comparative analysis to give us an overview of the data, the many layers in texts and the hidden communication they pass on to their consumers or their readership. She writes about variations in constructions, episodeoriented coverage that meets the media's nose for drama and sales, and shows stereotypes of gender, social class and ethnic origin. In her article, 'Femicide in a small Nordic Welfare Society: The case of Iceland', Freydís Jóna Freysteinsdóttir also analyses femicide in her country during the period from 1986-2015, utilizing data from media articles. The smallness of Iceland made it possible to include all cases in which 
a woman was murdered by an intimate partner during this period, creating a map to help trace the characteristics of these cases. The results are partly different from those in other parts of the world, but more similar to Scandinavian communities, thereby indicating regional differences.

Dabney P. Evans, Nancy S. DeSousa Williams, Jasmine D. Wilkins, Ellen D. Chiang, Olivia C. Manders and Maria A.F. Vertamatti analyse interview data from a municipality in São Paulo, Brazil, where violence against women is a widespread community problem. This is captured by the title of their article: 'He said he was going to kill me: Case studies of Attempted Intimate Femicide in São Paulo, Brazil.' They have selected two atypical cases based on the stories told by two women who survived murder attempts. By paying attention to details in how these women tell their stories in contexts where such violence has become the normal, they show the intricacy of telling and reasoning their own experiences in this context. Based on their modified grounded theory approach, they attempt to identify 'missed opportunities for intervention' and their analysis goes beyond the standard 'good practice' to professionals by nuancing terms and cultural storytelling in Brazil's 'culture of violence'. Their team had good knowledge of the Brazilian cultural context and language, and data was translated to English by a native speaker. This article shares a resemblance with the following one, Santiago Boira and Anita Nudelman's, 'Professionals' support role for survivors of femicide and relatives of victims: The case of Ecuador', which is also an interview study from South America. Their objective is to explore how femicide survivors and family members of victims perceive the assistance provided to them by professionals. In the Imbabura and Carchi Provinces, the fields of their study, people are involved in a complex system of interpersonal relationships and sociocultural norms and practices more pronounced in rural environments. The victims face barriers in their search for formal or informal help that may increase, instead of decrease, the risk of femicide. This accentuates the importance of locally grounded professional's intervention strategies. Based on their data from interviews with femicide survivors and victims' family members, they also go beyond practical matters, by discussing professional's communication skills, including skills in managing emotions and grief.

In 'Dowry, the Oppression of Women and Femicide in Bangladesh', written by Sadikur Rahman, we meet another region, Asia. He describes dowry practices and how they 
are linked with the killing of women. By introducing us to the historic and religious marriage practices in the region, he shows us the cultural variations in such practices and their frequently devastating effects on women (and some times in ways very different from the two studies from South America, which is another risk zone to women). In addition, he discusses their relation to a bride's marital welfare, colonialism and masculinization of the economy. The dowry practices in Bangladesh are often collective in the sense that they are family based, involving negotiations between the bride's and groom's families, transforming the woman and her body into a symbol of cultural intricacies that may result in murder, either committed by others or by herself in the form of suicide when life becomes too unbearable.

The last article, Anne Ryen's, ‘Categories and orthodoxies in studies on culture and femicide: An ethno-informed route to knowledge', is a methodological discussion of how to explore such a complex phenomenon as the culture of femicide. This is an epistemological criticism of the dominant interview studies, in which the author draws on the sociological debates of social order. She argues that culture cannot be reduced to a set of variables captured by asking questions. Rather than using externally imposed categories such as 'femicide', she advocates studies in which social scientists explore how local members talk about and categorize experiences such as a woman being killed. The author argues that we need to differentiate between using the categories that informants themselves use - as in most interview studies - and to study how they administer their descriptions and use them in specific contexts, such as in the ethnomethodological interest they exhibit in investigating their categories to find the activities in which to employ them.

The Journal of Comparative Social Work recognizes the many ways that social work is carried out globally. It aims at meeting people's social needs, which 'enable them to live in safety, independence and dignity' (2018). Therefore, the journal accentuates the importance of reflecting on the cultural and social norms of the relevant societies, which often also instigate and perpetuate pain, emotional turmoil and injustice. These cultural norms and practices can represent hurdles to safe and independent lives, as well as the knowledge about how they operate, being crucial to professionals engaged in social work in formal or informal sectors, both those professionally trained and voluntary workers. This will contribute to their ability to care for and assist people in 
need of such help, allowing them to overcome the lack of trust and rejection of services. The articles in this special issue meet the Journal's criteria, and show the intricacy of femicide, especially in gendered and violent societies, but also in regions of the world described as peaceful and associated with gender equality. Based on data from different world regions, the articles show the impact of contextual matters that frame different issues related to women being killed by intimate partners assumed to be their friends and protectors. The articles clearly illustrate the cultural aspects of institutions such as marriage, partners, families and in-laws, and the many ways to construct social order, even sometimes relating to murders as normal exceptions to such orders in ways that may even legitimize a lover, fiancé, wife or mother being killed. These reflect the many categories or 'tags' imposed on women, and bring forth moral implications which make women and their lives part of a bigger context that tends to allocate them less favourable positions in society. Because gender is closely interconnected with power, it has historically had disastrous consequences for women. The researchers' interest in femicide stories related by the media, victims and family members through different methodologies also represent academic contributions to fight gendered injustice, and prevent violence and femicide. In their own ways, all the articles meet the journal's primary interest in comparative studies and discussions of practice, since the single-site studies also offer knowledge across geographical and cultural settings.

We want to thank all the authors for their contributions, journal editor Kjersti Ørvig for the very good and positive communication, and Maury Saslaff for basking with grammar and language in our manuscripts from authors across the world, editors included. Special thanks as well for your patience and alertness until the very last minute!

We would also like to appreciate the dedicated work of all our reviewers (in alphabetical order):

- Santiago Boira

- Giorgia Dona

- Maria Lameiras Fernandez

- Maria Jose Magalhaes

- Chaime Marcuelo

- Vilana Pilinkaite Sotirovic

- Elena Rousou 
- Irene Trysnes

- Tiko Tsomaia.

To sum up, this was a great team and we have enjoyed all the various legs in a long journey. 


\section{References}

Bott, S., Guedes, A., Goodwin, M., \& Mendoza, J. A. (2013). Violence against women in Latin America and the Caribbean: A comparative analysis of populationbased data from 12 countries. Washington: Pan American Health Organization $\&$ the Centers for Disease Control and Prevention.

Firth, P. (2014). Violence Against Women: So Common, It's Cultural. Firesteel Network, Washington. Retrived from: http://firesteelwa.org/2014/10/violenceagainst-women-so-common-its-cultural/

Gokal, S., \& Dughman Manzur, S. (2013). Religion, Culture and Tradition: Strengthening Efforts to Eradicate Violence against Women. Ontario: Association for Women's Rights in Development. Retrieved from: https://www.awid.org/sites/default/files/atoms/files/religion_culture_and_tradition _strengthening_efforts_to_eradicate_violence_against_women.pdf\%20\%20 (accessed May 27, 2018).

Journal of Comparative Social Work, (2018). Retrieved from https://journals.uis.no/index.php/JCSW/about

Kalra, G., \& Bhugra D. (2013). Sexual violence against women: Understanding crosscultural intersections. Indian Journal of Psychiatry, 55(3), 244-249. doi:10.4103/0019-5545.117139 Retrieved from: https://www.ncbi.nlm.nih.gov/pmc/articles/PMC3777345/

Kapardis, A., Costanza Baldry, A., \& Konstantinou, M. (2017). A Qualitative Study of Intimate Partner Femicide and Orphans in Cyprus. Qualitative Sociology Review, 13(3), 80-100. Retrieved from: http://www.qualitativesociologyreview.org/ENG/Volume42/QSR_13_3_Kapardis _Baldry_Konstantinou.pdf

Kouta, C., Rousou, E., Freysteinsdóttir, F., Boira, S., \& Naudi, M. (2017). Gender and Socio-Cultural Perspectives through Femicide Case Studies, Journal of Community Medicine \& Health Care, 2(2), 1013.

Ryen, A. (2008). "Trust in Cross-Cultural Research. The Puzzle of Epistemology, Research Ethics and Context". Qualitative Social Work, 7(4), 448-465.

Saccomano, C. (2015). The causes of famicide in Latin America. Student paper series 24. Barcelona: Institut Barcelona Estudis Internationals. Retrieved from: http://www.ibei.org/ibei_studentpaper24_71980.pdf 
Starr, C. (2017). When Culture Matters: Frame Resonance and Protests against Femicide in Ciudad Juarez, Mexico. The Qualitative Report 22(5), 1359-1378.

The Vienna Declaration on Femicide. Retrieved from:

http://www.ipetitions.com/petition/vienna-declaration-onfemicide/

WHO (2009). Violence prevention - The evidence. Changing cultural and social norms that support violence. Retrieved from:

http://www.who.int/violence_injury_prevention/violence/norms.pdf

WHO (2012). Understanding and addressing violence against women. Femicide. Retrieved from:

http://apps.who.int/iris/bitstream/10665/77421/1/WHO_RHR_12.38_eng.pdf 